12 Shekelle RB, Schoenberger JA, Stamler J. Correlates of the JAS type A behavior pattern score. J Chronic Dis 1976;29:381-94.

13 Haynes SG, Feinleib M, Levine S, Scotch N, Kannel WB. The relationship of psychosocial factors to coronary heart disease in the Framingham study II. Prevalence of coronary heart disease. Am J Epidemiol 1978; 107:384-402.

14 French-Belgian Collaborative Group. Ischaemic heart disease and psychological patterns. Adv Cardiol 1982;29:25-31.

15 Freeman $Z$. Is type A behaviour a cause of coronary heart disease? Med f Aust 1986;145:262-70. 16 Rosenman RH, Brand RJ, Jenkins CD, Friedman M, Straus R, Wurm M. Coronary heart disease in the Western Collaborative Group study: final follow-up experience of $8^{1 / 2}$ years. $\mathscr{f A M A}$ in the Western

17 Kittel F. Type A and other psychosocial factors in relation to CHD. In: Schmidt TD, Dembroski TD, Blumchen C, eds. Biological and psychological factors in cardiovascular disease. Berlin Springer Verlag, 1986:63-84.
18 Shekelle RB, Hulley SB, Neaton JD, et al. The MRFIT behavior pattern study. II: type A behavior and the incidence of coronary heart disease. Am $\mathcal{J}$ Epidemiol 1985;122:559-70.

19. Jenkins CD, Rosenman RH, Zyzanski SJ. Prediction of clinical coronary heart disease by a test of the coronary-prone behavior pattern. N Engl f Med 1974;290:1271-5.

20 Cohen JB, Reed D. The type A pattern and coronary heart disease among Japanese men in Hawaii. I Behav Med 1985;4:343-52.

21 Haynes SG, Feinleib M, Kannel WB. The relationship of psychosocial factors to coronary heart disease in the Framingham study. III: eight-year incidence of coronary heart disease. Am $\mathcal{J}$ Epidemiol 1980;111:37-58.

22 Shekelle RB, Gale M, Ostfeld A, Paul O. Hostility, risk of coronary heart disease and mortality. Psychosom Med 1983;45:109-14.

23 Manuck SB, Kaplan TR, Matthews KA. Behavioral antecedents of coronary heart disease and atherosclerosis. Anteriosclerosis 1986;6:2-14.

(Accepted 22 May 1987)

\title{
Lethal malformations and perinatal mortality: a 10 year review with comparison of ethnic differences
}

\author{
I D YOUNG，M CLARKE
}

\begin{abstract}
During 1976 to 1985 perinatal mortality in Leicestershire decreased from 21 to 9.5 per 1000 births. Throughout this period the incidence of lethal malformations, excluding neural tube defects, remained relatively constant at around 1.8 per 1000 births. Analysis of the malformations present in 201 lethally malformed babies showed that $147(73 \%)$ had a disorder carrying a recurrence risk of $1 \%$ or greater. Only $7 \%$ of these malformations might have been predicted from the family history or advanced maternal age. The incidence of lethal malformations was significantly increased in the Asian population, largely because of an excess of autosomal recessive disorders.

The contribution of lethal malformations to perinatal mortality has almost doubled over the past 10 years and is likely to increase despite prenatal diagnosis and improvements in obstetric and paediatric services.
\end{abstract}

\section{Introduction}

Malformations account for a substantial proportion of perinatal mortality in the United Kingdom, with figures of $26 \%$ and $34 \%$ having been observed in recent studies. ${ }^{12}$ Given the decline in other causes of perinatal death and the recent unexplained reduction in the incidence of neural tube defects, ${ }^{3}$ attention will probably focus increasingly on babies with malformations other than neural tube defects, whose relative contribution to perinatal mortality is likely to increase despite existing or planned improvements in obstetric and paediatric services.

In 1976 a comprehensive survey of perinatal mortality was launched in Leicestershire (population 833000), a county which readily lends itself to epidemiological study as obstetric and paediatric services are based in two centrally located teaching hospitals, thus facilitating the collection of relevant information. Using data from the first 10 years of this survey we reviewed the

Departments of Child Health and Community Health, University of Leicester, Leicester LE2 7LX

I D YOUNG, MD, MRCP, senior lecturer in child health (clinical genetics) M CLARKE, DPH, FFCM, professor of epidemiology

Correspondence to: Dr I D Young, Department of Child Health, Clinical Sciences Building, Leicester Royal Infirmary, PO Box 65, Leicester LE2 7LX. records of babies dying as a result of malformations, excluding neural tube defects. The objectives of this study were $(a)$ to ascertain whether there had been any change in the overall incidence of lethal malformations over 10 years; (b) to establish the aetiological range and its genetic component; $(c)$ to estimate the possible impact of genetic counselling and prenatal diagnostic surveillance; and $(d)$ to identify possible ethnic differences.

\section{Methods}

Babies were ascertained through the records of the Leicestershire perinatal mortality survey, full details of which have been recorded elsewhere. ${ }^{45}$ Strenuous efforts were made to review the records of all babies along with necropsy reports, radiographs, and clinical photographs. Babies were included in the study only if death was due primarily to a malformation, so that babies who had a relatively minor abnormality, which was coincidental rather than causally related to their death, were not included. When appropriate recourse was made to expert opinion and the London dysmorphology database to help establish the diagnosis. ${ }^{6}$

The results presented below refer to lethal malformations other than isolated non-syndromic neural tube defects.

\section{Results}

\section{INCIDENCE OF LETHAL MALFORMATIONS}

Table I gives the birth statistics for Leicestershire for 1976-85. During this period 208 babies died in the perinatal period primarily as the direct result of a malformation or malformations: an overall incidence of $1.80 \mathrm{per}$

TABLE I-Birth statistics for Leicestershire 1976-85

\begin{tabular}{|c|c|c|c|c|c|c|c|}
\hline & \multicolumn{3}{|c|}{ Deaths due to malformations } & \multirow{2}{*}{$\begin{array}{l}\text { Total perinatal } \\
\text { deaths }\end{array}$} & \multicolumn{3}{|c|}{ Total births } \\
\hline & White & Asian & Total & & White & Asian & Total \\
\hline 1976 & 15 & 3 & 18 & 230 & 9752 & 1123 & 10875 \\
\hline 1977 & 20 & 4 & 24 & 190 & 9549 & 1286 & 10835 \\
\hline 1978 & 19 & 4 & 23 & 196 & 9784 & 1276 & 11060 \\
\hline 1979 & 19 & 4 & 23 & 172 & 10388 & 1366 & 11754 \\
\hline 1980 & 18 & 4 & 22 & 151 & 10822 & 1524 & 12346 \\
\hline 1981 & 16 & 5 & 21 & 118 & 10273 & 1518 & 11791 \\
\hline 1982 & 12 & 4 & 16 & 130 & 10061 & 1496 & 11557 \\
\hline 1983 & 16 & 7 & 23 & 122 & 9979 & 1565 & 11544 \\
\hline 1984 & 11 & 4 & 15 & 101 & 10161 & 1625 & 11786 \\
\hline 1985 & 18 & 5 & 23 & 114 & 10375 & 1582 & 11957 \\
\hline Total & 164 & 44 & 208 & 1524 & 101144 & 14361 & 115505 \\
\hline
\end{tabular}


1000. Although the number of babies dying as a result of malformations remained relatively constant throughout the study period, the overall perinatal mortality rate fell from 21 per 1000 in 1976 to $9 \cdot 5$ per 1000 in 1985. These trends are shown in the figure.

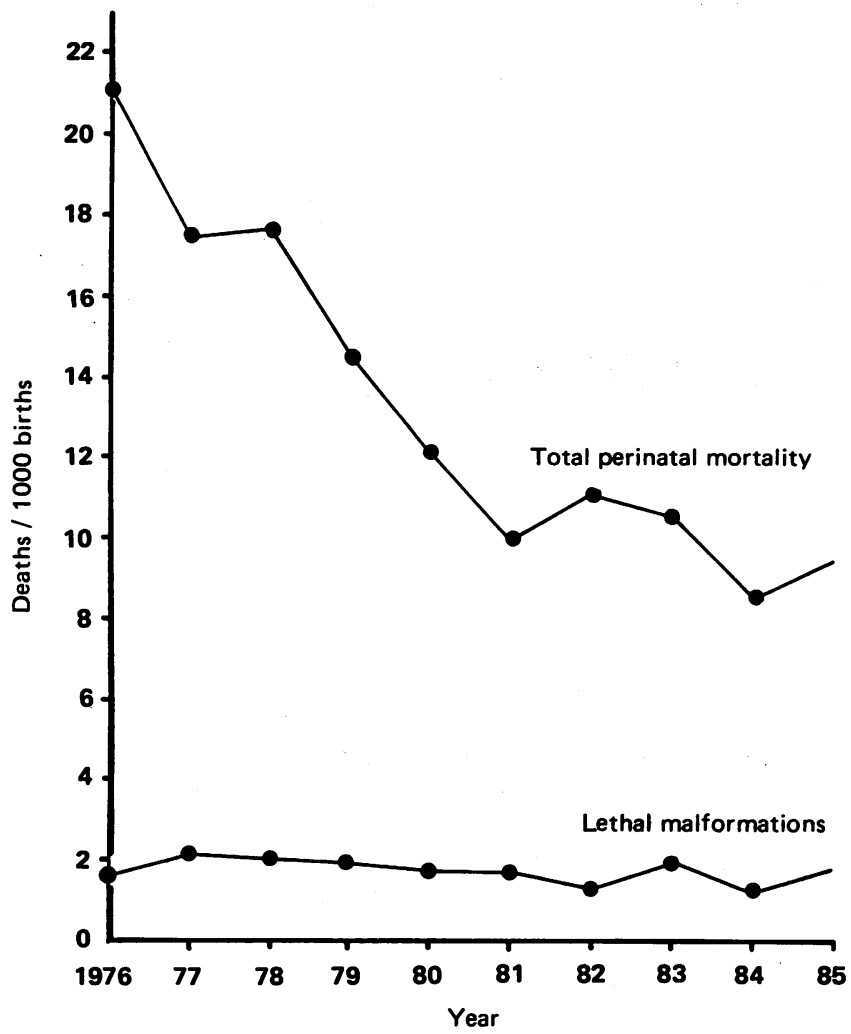

Overall perinatal mortality and contributing lethal malformations, excluding neural tube defects, in Leicestershire 1976-85.

\section{CAUSES AND GENETIC CONTRIBUTION}

The hospital records of 201 of these babies were reviewed. For 21 babies no clear diagnosis could be established, either because investigation or documentation, or both, were incomplete or because the pattern of abnormalities did not match any known disorder or syndrome.

Table II shows that most of the remaining 180 babies had a disorder that was at least partly genetic in origin - that is, chromosomal, single gene, or multifactorial. Thirty eight ( $21 \%$ ) babies had a chromosomal abnormality, and $24(13 \%)$ had a known autosomal recessive disorder (table III). In addition $12(7 \%)$ babies had disorders showing aetiological heterogeneity; this may include recessive inheritance-that is, renal dysplasia, diaphragmatic agenesis, lissencephaly, and ill defined short limbed dwarfism. Disorders showing multifactorial inheritance or known to convey a recurrence risk of $1 \%$ or greater, accounted for $73(41 \%)$ deaths. A non-genetic aetiology could be established with certainty in only $23(13 \%)$ of the 180 study babies with a known diagnosis, although an additional 10 , indicated in table II as having a recurrence risk of less than $1 \%$, almost certainly had a non-genetic cause.

\section{POTENTIAL FOR PREVENTION}

The 180 study babies contained four sibling pairs, three with an autosomal recessive disorder (Meckel's syndrome, multiple pterygia and polycystic kidneys) and one with an inherited chromosome abnormality. There were also three babies with an affected sibling born before 1976 in whom the diagnoses were idiopathic hydrops, Robert's syndrome, and diaphragmatic agenesis. The father of one baby with trisomy 18 had a child with trisomy 21 in a previous marriage, and one baby with complex congenital heart disease had an older sibling with corrected transposition of the great vessels. Thus nine $(5 \%)$ of the study babies had a family history of abnormality, so that it could be argued that these nine births were "preventable." In addition,
TABLE II-Cause of death of babies in the study (recurrence risks(\%) in parentheses)

\begin{tabular}{|c|c|c|c|c|c|c|}
\hline & \multicolumn{3}{|c|}{ White } & \multicolumn{3}{|c|}{ Asian } \\
\hline & No & & Rate/10000 & No & & Rate/10000 \\
\hline $\begin{array}{l}\text { Chromosomal: } \\
\text { Trisomy } 13(1 \cdot 3) \\
\text { Trisomy } 18(1 \cdot 3) \\
\text { Trisomy } 21(1 \cdot 3) \\
\text { Other, inherited }(5-10) \\
\text { Other, de novo }(1 \cdot 3)\end{array}$ & $\left.\begin{array}{r}8 \\
13 \\
5 \\
2 \\
4\end{array}\right\}$ & 32 & $3 \cdot 2$ & $\left.\begin{array}{l}0 \\
2 \\
1 \\
2 \\
1\end{array}\right\}$ & 6 & $4 \cdot 2$ \\
\hline $\begin{array}{l}\text { Single system: } \\
\text { Cardiac } \\
\text { Hypoplastic left heart (2) } \\
\text { Complex (1) } \\
\text { Isomerism (4-5) } \\
\text { Other }(1-4)\end{array}$ & $\left.\begin{array}{r}11 \\
8 \\
3 \\
13\end{array}\right\}$ & 35 & $3 \cdot 5$ & $\left.\begin{array}{l}3 \\
1 \\
1 \\
2\end{array}\right\}$ & 7 & $4 \cdot 9$ \\
\hline $\begin{array}{l}\text { Renal* } \\
\text { Bilateral agenesis }(3-8) \\
\text { Polycystic kidneys }(25) \\
\text { Dysplastic kidneys }(1-25) \\
\text { Urethral obstruction }(<1)\end{array}$ & $\left.\begin{array}{l}8 \\
3 \\
3 \\
3\end{array}\right\}$ & 17 & $1 \cdot 7$ & $\left.\begin{array}{l}4 \\
2 \\
0 \\
1\end{array}\right\}$ & 7 & $4 \cdot 9$ \\
\hline $\begin{array}{l}\text { Pulmonary } \\
\text { Diaphragmatic hernia (2) } \\
\text { Diaphragmatic agenesis }(2-25) \\
\text { Pulmonary hypoplasia }(<1)\end{array}$ & $\left.\begin{array}{l}9 \\
3 \\
1\end{array}\right\}$ & 13 & $1 \cdot 3$ & $\left.\begin{array}{l}1 \\
0 \\
0\end{array}\right\}$ & 1 & $0 \cdot 7$ \\
\hline $\begin{array}{l}\text { Skeletal (2-25) } \\
\text { Gastrointestinal (<1) } \\
\text { Cerebral } \\
\text { Hydrocephalus (3) } \\
\text { Holoprosencephaly (6) } \\
\text { Other (0-5) }\end{array}$ & $\left.\begin{array}{l}8 \\
3 \\
4 \\
3 \\
3\end{array}\right\}$ & 10 & $1 \cdot 0$ & $\left.\begin{array}{l}2 \\
1 \\
0 \\
0 \\
1\end{array}\right\}$ & 1 & 0.7 \\
\hline Multisystem recessive syndromes $\nmid(25)$ & 3 & & $0 \cdot 3$ & 11 & & $7 \cdot 7$ \\
\hline $\begin{array}{l}\text { Miscellaneous non-genetic } ¥(<1) \text { : } \\
\text { Amniotic bands } \\
\text { Twin-twin disruption } \\
\text { VATER association } \\
\text { Cloacal abnormality } \\
\text { Sirenomelia } \\
\text { Hydrops (cytomegalovirus infection) }\end{array}$ & $\left.\begin{array}{l}3 \\
2 \\
7 \\
2 \\
1 \\
1\end{array}\right\}$ & 16 & $1 \cdot 6$ & $\left.\begin{array}{l}2 \\
2 \\
2 \\
0 \\
1 \\
0\end{array}\right\}$ & 7 & $4 \cdot 9$ \\
\hline $\begin{array}{l}\text { Cause unknown (?) } \\
\text { Notes unobtainable (?) }\end{array}$ & $\begin{array}{r}20 \\
7\end{array}$ & & & $\begin{array}{l}1 \\
0\end{array}$ & & \\
\hline Total\$ & 164 & & $16 \cdot 2$ & 44 & & $30 \cdot 6$ \\
\hline
\end{tabular}

TABLE III-Babies in the study with a definite autosomal recessive disorder

\begin{tabular}{llc}
\hline & White & Asian \\
\hline Multisystem syndrome: & 1 & \\
$\quad$ Meckel & & 3 \\
Multiple pterygia & $1^{\star}$ & 1 \\
$\begin{array}{l}\text { Pena Shokeir } \\
\text { Robert's }\end{array}$ & 1 & \\
Smith-Lemli-Opitz II & & $1^{\star}$ \\
$\quad$ Hydrops & 3 & 2 \\
Single system disorder: & $1^{\star}$ & \\
$\quad$ Polycystic kidneys & 3 & \\
Diaphragmatic agenesis & 1 & 13 \\
Campomelic dysplasia & 11 & $9 \cdot 1$ \\
\hline Total Noonan & 1.09 & \\
Rate/10000† &
\end{tabular}

$\star$ Previously affected sibling. $t \chi^{2}=38.09 ; \mathrm{p}<0.001$ (white $v$ Asian babies).

three of the mothers of babies with non-disjunction were aged 38, 39, and 39 years, so these three births, each affected by trisomy 18 , might also be deemed "preventable."

\section{ETHNIC DIFFERENCES}

From tables I and II it is clear that there was a highly significant difference in the death rates due to malformations between babies born to white mothers and those born to mothers of Asian (mainly Indian subcontinent) origin. This was most striking for autosomal recessive disorders (table III). Six of the 13 babies with a definite autosomal recessive disorder born to Asian parents were known to have consanguineous parents (four Moslem and two Hindu). Five had non-consanguineous Hindu parents, and the 
remaining two were born to a Hindu couple and a Moslem couple for whom details of consanguinity were not available.

The other significant differences were for renal abnormalities and miscellaneous non-genetic conditions. When the two babies with polycystic kidney disease born to consanguineous Asian parents were excluded a comparison of the number of babies with renal disorders (17 white $v$ five Asian) was no longer significantly different $\left(\chi^{2}=2 \cdot 10 ; p=0 \cdot 1\right)$. Two of the seven Asian babies in the miscellaneous non-genetic group were born to Hindu parents (one with amniotic bands and one with the VATER association (vertebral defects, anal atresia, tracheo-oesophageal fistula, radial and renal dysplasia)) and two to Moslem parents (one with amniotic bands and one with the VATER association). The remaining three Asian babies were delivered to Sikh parents: one of these babies had sirenomelia while the other two had gross structural disruptive defects resulting from artery-artery anastomoses in twins.

\section{Discussion}

These results show that, although the incidence of lethal malformations has remained relatively constant over 10 years, their contribution to perinatal mortality has increased from $10 \%$ in $1976-7$ to $18 \%$ in $1984-5$. It is disappointing that the recent unexplained decline in the incidence of neural tube defects has not occurred with other lethal malformations. Presumably this is due, at least in part, to amelioration of the poorly understood environmental factors that contribute to neural tube defects, whereas the sizeable genetic component in other lethal malformations has remained unchanged.

Our results confirm previous studies in showing a major genetic contribution to lethal malformations. ${ }^{79}$ Of the 201 babies in the study whose records were available for review $147(73 \%)$ had a disorder with a recurrence risk of $1 \%$ or greater. When the 21 babies in whom no diagnosis could be established were excluded this proportion rose to $82 \%$, a figure that corresponds closely to that of $79.5 \%$ obtained in an American study. ${ }^{9}$ This shows the importance of full assessment and investigation of these infants. ${ }^{10}$ Experience in Leicester suggests that this is a worthwhile exercise. Twenty of the 21 undiagnosed cases in this survey came from the first seven years of the study period, with only one from the last three years.

The existence of a lethal malformation might have been predicted on the basis of family history or advanced maternal age in only 12 $(7 \%)$ of the babies, so that even the most enthusiastic prenatal diagnostic programme would have had little effect on overall perinatal mortality. The introduction of routine diagnostic ultrasonography during the second trimester, as advocated by Campbell and Smith, "1 would be expected to detect about half of these casesthat is, those with major structural abnormalities of the brain, heart, kidneys, or skeleton. This development, however, will not be easily achieved on a large scale in an atmosphere of economic stringency, nor will it necessarily be welcomed by all parents and doctors.

Increased perinatal mortality rates in Asian populations have been noted elsewhere in the United Kingdom and are likely to be due to a combination of social, environmental, and genetic factors. ${ }^{12}$ The increased incidence of lethal malformations in babies of Asian origin noted in this study can be attributed largely to an excess of autosomal recessive disorders, chiefly Meckel's syndrome, which seems to be particularly common in Gujaratis, ${ }^{13}$ plus other rare recessive syndromes, which in many instances are the consequence of consanguineous relationships. Several groups in Britain are looking prospectively at the morbidity and mortality associated with consanguineous marriages in British ethnic minorities, although it may be that the social and family benefits of consanguinity outweigh its possible deleterious genetic effects.

Not all of the excess mortality in the Asian babies, however, can be attributed directly to genetic factors as there was also a significant excess of non-genetic lethal malformations in the Asian group. Most of these babies were born to Hindu and Sikh parents, who rarely practise consanguinity. Thus it is unlikely that rare recessive disorders have been misdiagnosed as non-genetic conditions. The Birmingham studies have also noted an excess of malformations in the non-consanguineous Indian population, so that social and environmental factors such as diet may be influential. ${ }^{12} 14$

This study confirms that the contribution of lethal malformations to perinatal mortality has almost doubled over the past 10 years, and presumably will continue to rise if further inroads are made into the prevention of other causes of death in the perinatal period. This, combined with the substantial genetic element in the aetiology of these malformations and its associated implications for future pregnancies, shows the importance of assessing these babies, both individually and on a larger scale, as an important component of perinatal mortality surveys.

We thank Elizabeth Mason, Ivy Rushby, Penny Marston, and Dr Andrew Rickett for their help in this study, and in particular Professor John MacVicar for his support and encouragement. The Leicestershire perinatal mortality survey, which is organised through the Department of Community Health in collaboration with the Department of Obstetrics and Gynaecology, is funded by the Leicestershire Health Authority.

\section{References}

1 Mcllwaine GM, Howat RCL, Dunn F, Macnaughton MC. The Scottish perinatal mortality survey. Br Med F 1979;ii:1103-6.

2 Mutch LMM, Brown NJ, Speidel BD, Dunn PM. Perinatal mortality and neonatal survival in Avon: 1976-9. BrMed f 1981;282:119-22.

3 Seller MJ. Unanswered questions on neural tube defects. Br Med $\mathcal{F}$ 1987;294:1-2.

4 Clarke $M$, Clayton $D$. The design and interpretation of case-control studies of perinatal mortality. Am f Epidemiol 1981;113:636-45.

5 Clarke M, Clayton D. Quality of obstetric care provided for Asian immigrants in Leicestershire. BrMed F 1983;286:621-3.

6 Winter RM, Baraitser M, Douglas JM. A computerised data base for the diagnosis of rare dysmorphic syndromes. I Med Genet 1984;21:121-3.

7 MacLeod PM, Dill F, Hardwick DF. Chromosomes, syndromes and perinatal deaths: the genetic counselling value of making a diagnosis in a malformed abortus, stillborn and deceased

8 Young ID, Rickett AB, Clarke M. Genetic analysis of malformations causing perinatal mortality. f Med Genet 1986;23:58-63.

9 Mueller RF, Sybert VP, Johnson J, Brown ZA, Chen WJ. Evaluation of a protocol for postmortem examination of stillbirths. $N$ Engl f Med 1983;309:586-90.

10 Winter RM. The malformed fetus and stillbirth: Whose patient? Br $\mathcal{O}$ Obstet Gynaecol 1983;90: 499-500.

11 Campbell S, Smith P. Routine screening for congenital abnormalities by ultrasound. In: Prenatal diagnosis. Proceedings of the Eleventh Study Group of the Royal College of Obstetricians and diagnosis. Proceedings of the Eleventh Study Group of the Royal College of Obstetricians
Gynaecologists. London: Royal College of Obstetricians and Gynaecologists, 1984:325-30.

12 Terry PB, Condie RG, Settatree RS. Analysis of ethnic differences in perinatal statistics. Br Med J 1980;281:1307-9.

13 Young ID, Rickett AB, Clarke M. High incidence of Meckel's syndrome in Gujarati Indians. J Med Genet 1985;22:301-4.

14 Terry PB, Mathew PM, Condie RG, Bissenden JG. Ethnic differences in the distribution of congenital malformations. Postgrad Med J 1983;59:657-8.

(Accepted 29 April 1987) 